\title{
Giant-cell Arteritis of the Ovarian Arteries: A Rare Manifestation of a Common Disease
}

\author{
Prisca Theunissen ${ }^{1}$, Mike Kliffen ${ }^{2}$, Ad Dees ${ }^{1}$ \\ ${ }^{1}$ Department of Internal Medicine, Ikazia Ziekenhuis, Rotterdam, The Netherlands \\ ${ }^{2}$ Department of Clinical Pathology, Maasstad Ziekenhuis, Rotterdam, The Netherlands
}

Received: 10/11/2017

Accepted: 22/01/2018

Published: $26 / 02 / 2018$

How to cite this article: Theunissen P, Kliffen M, Dees A. Giant-cell arteritis of the ovarian arteries: a rare manifestation of a common disease. EJCRIM 2018;5: doi:10.12890/2018_000779.

Conflicts of Interests: The Authors declare that there are no competing interests.

This article is licensed under a Commons Attribution Non-Commercial 4.0 License

\section{ABSTRACT}

We describe a 58-year-old woman presenting with headache and an elevated erythrocyte sedimentation rate (ESR), who was diagnosed with and successfully treated for giant-cell arteritis (GCA). Seven months after the end of treatment, ovarian GCA was incidentally found after ovariectomy for a simple cyst. GCA of extracranial vessels like the ovarian arteries is rare. Nevertheless, we stress that extracranial GCA should be considered in patients older than 50 years with an elevated ESR, even if a temporal artery biopsy is negative or specific symptoms are absent. Moreover, we discuss the importance of imaging techniques when GCA of the extracranial large vessels is suspected.

\section{LEARNING POINTS}

- Although rare, ovarian arteries can be involved in giant-cell arteritis (GCA).

- Extracranial GCA should be considered in the differential diagnosis of patients aged 50 years or older with an elevated ESR, even if temporal artery biopsy is negative or specific symptomatology of GCA is absent.

- If GCA is suspected but the origin is unclear, an MRA or PET-CT scan should be performed to screen for GCA of extracranial arteries.

\section{KEYWORDS}

Giant-cell arteritis, ovarian arteries, rare manifestation, vasculitis in female genital tract

\section{CASE DESCRIPTION}

In April 2010, a 58-year-old woman, with a history of nicotine abuse and a simple ovarian cyst, presented with severe headache (without tenderness of the temporal artery), malaise and an elevated erythrocyte sedimentation rate (ESR) of $107 \mathrm{~mm}$ in the first hour (normal $<20 \mathrm{~mm} /$ hour). CRP and liver enzyme levels were normal. Oral prednisolone therapy (30 mg daily) was started by her general physician. However, as her complaints persisted while being treated for several weeks, she was referred to the hospital. The clinical and laboratory parameters, in particular the patient's age ( $>50$ years old), the new onset of the headache and the increased ESR, fulfilled at least three classification criteria for giant-cell arteritis (GCA) ${ }^{[1]}$. The issue of a late temporal artery biopsy (TAB) to prove GCA, taking into account the pretreatment, was discussed, but a TAB was refused by the patient. A positron emission tomography (PET)-CT scan was also not performed, as this was not yet part of the standard work-up for GCA at that time. Since the suspicion of GCA was nevertheless high, the oral 
prednisolone therapy was continued, now using an increased dosage of $60 \mathrm{mg}$ daily. During 6 weeks of high-dose prednisolone treatment, the ESR normalized (19 mm/hour) and the headache decreased. However, upon tapering of the prednisolone, the severe headache and elevated ESR (68 mm/hour) immediately returned. Therefore, prednisolone was further tapered, and a subsequent prolonged, steroidsparing treatment with methotrexate (10 mg daily for 10 months) was initiated. As a result, the ESR again normalized and the headache, after still being intermittently present during the first months, finally resolved. Seven months after the end of treatment, a laparoscopic bilateral ovariectomy was performed in order to remove a slowly growing simple ovarian cyst. Histological examination showed, in addition to a benign ovarian cyst, an infiltrate of lymphocytes, macrophages and giant cells in the walls of the hilar arteries of both ovaries, indicative of ovarian artery GCA (Fig. 1A,B). Since the patient did not have any complaints postoperatively, further treatment was not required.

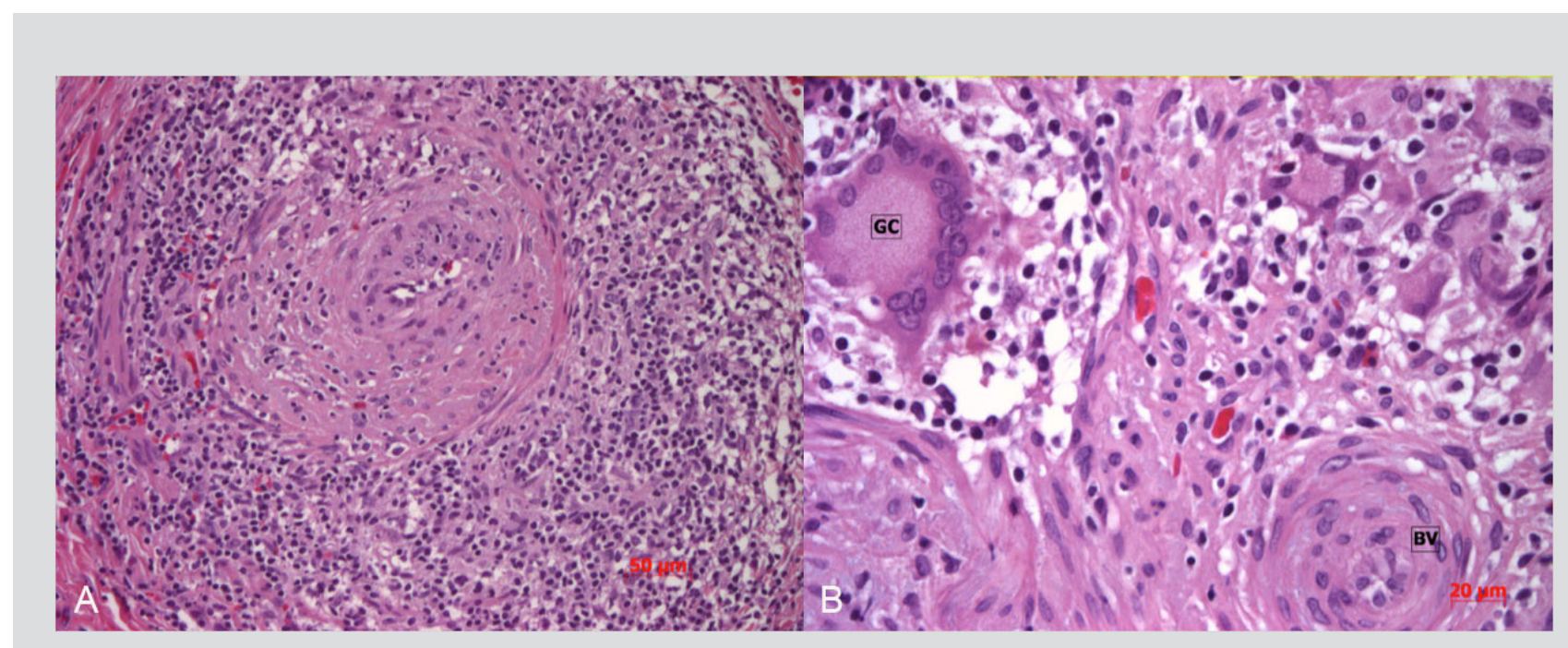

Figure 1. Histopathological examination of the ovarian tissue showed a giant-cell arteritis of the ovarian arteries, characterized by (A) a dense infiltrate and (B) multiple giant cells (GC) in the wall of the blood vessel (BV)

\section{DISCUSSION}

GCA is a systemic vasculitis of medium- to large-sized arteries, typically involving the temporal artery (temporal arteritis) ${ }^{[2,3]}$. GCA is the most common form of systemic vasculitis in adults, with an annual incidence of 20 per 100,000 individuals among Northern Europeans above 50 years of age ${ }^{[4]}$. GCA is caused by dendritic cells in the vessel wall, recruiting T-cells and macrophages to locally form a granulomatous infiltrate, characterized by giant cells (fused macrophages) ${ }^{[5]}$. GCA most commonly involves the superficial temporal artery, but it can also affect the carotid arteries, the vertebral arteries, the subclavian, axillary and proximal brachial arteries, the ascending aorta and the coronary arteries $^{[3]}$. Less frequently involved are the descending aorta and mesenteric, renal, iliac and femoral arteries ${ }^{[4]}$. Rarely, GCA of the arteries of the lungs, cervix, breast or ovaries is found (see supplementary references 1-4). Symptoms may include headache, tenderness of the scalp, jaw claudication, tinnitus, diplopia, and, if occlusion of the ophthalmic artery occurs, the feared complication of sudden and irreversible blindness ${ }^{[2,3]}$. Systemic manifestations like fever, fatigue and malaise may also be present ${ }^{[6]}$. While clinical and laboratory parameters can raise suspicion, a TAB is needed for a definitive diagnosis of $\mathrm{GCA}^{[3]}$. GCA is treated with high-dose prednisolone, or alternatively with methotrexate or azathioprine ${ }^{[4]}$.

The above-described case of GCA is remarkable, since GCA of the ovarian arteries is rare and has only sporadically been reported before (see supplementary references 5-13). Also in the few previous reports, GCA of the ovarian arteries was detected incidentally, by histopathological examination after an ovariectomy for a lesion unrelated to GCA. In general, most of the incidental GCA discoveries concerned GCA in the female gynaecological tract or in the breasts (see supplementary references 2-13). Presumably, this is partly due to the high number of mastectomies, hysterectomies and ovariectomies performed.

Since, in our case, the patient presented with new-onset headache, the suspicion of GCA was quickly raised and treatment was immediately started. However, in most of the previously reported cases of GCA in the female genital tract, patients were either asymptomatic or experiencing vague systemic manifestations like malaise, fever, anaemia and weight loss. In these patients, the diagnosis was not considered 
until GCA was coincidentally found in surgically removed tissue, and consequently the appropriate treatment was only started a long time after the initial complaints. Moreover, there may be patients with gynaecological GCA who have never been diagnosed (since they did not undergo surgery) and therefore have not been treated at all. Of note, treatment does not seem to be required in patients with gynaecological GCA who are asymptomatic ${ }^{[7]}$.

As mentioned previously, a TAB is necessary to diagnose GCA. However, in up to $42 \%$ of the GCA patients with extracranial large-vessel manifestation, TAB is negative ${ }^{[8]}$. Therefore, if GCA is suspected, but the clinical criteria are not fulfilled and/or the TAB is negative, PET-CT is needed to investigate whether one or more of the above-described arteries are affected by GCA. Importantly, PET-CT is only able to detect inflammatory vessel wall disease of the larger arteries ${ }^{[9]}$. MRA can be used to look for stenosis in the smaller vessels (although it cannot discriminate between arteritis and atherosclerosis) ${ }^{[3]}$.

In our patient, an active infiltrate was found within the ovarian artery walls despite prior extensive treatment. Previous studies showed that corticosteroid treatment usually improves the clinical symptoms and laboratory values, but often fails to eliminate the vascular inflammation ${ }^{[10]}$. Still, it could be argued from clinical experience that current corticosteroid treatment regimens are sufficient to prevent most of the vascular complications and systemic manifestations of GCA ${ }^{[10]}$.

In conclusion, besides its well-known manifestation in the temporal artery, GCA can be present at many other sites of the body, such as the female genital tract. Therefore, extracranial GCA should be considered in the differential diagnosis of patients aged 50 years or older with an elevated ESR, even if TAB is negative and specific symptomatology of GCA is absent. The imaging tools of PET-CT and MRA, which are widely available nowadays, have become important aids in the diagnosis of rare presentations of GCA.

\section{REFERENCES}

1. Hunder GG, Bloch DA, Michel BA, Stevens MB, Arend WP, Calabrese LH, et al. The American College of Rheumatology 1990 criteria for the classification of giant cell arteritis. Arthritis Rheum 1990;33:1122-8.

2. Buttgereit F, Dejaco C, Matteson EL, Dasgupta B. Polymyalgia rheumatica and giant cell arteritis: a systematic review. JAMA 2016;315:2442-58.

3. Ninan J, Lester S, Hill C. Giant cell arteritis. Best Pract Res Clin Rheumatol 2016;30:169-88.

4. Weyand CM, Goronzy JJ. Clinical practice. Giant-cell arteritis and polymyalgia rheumatica. N Engl J Med 2014;371:50-7.

5. Wang AL, Raven ML, Surapaneni K, Albert DM. Studies on the histopathology of temporal arteritis. Ocul Oncol Pathol 2017;3:60-5.

6. Calamia KT, Hunder GG. Giant cell arteritis (temporal arteritis) presenting as fever of undetermined origin. Arthritis Rheum 1981;24:1414-18.

7. Marrogi AJ, Gersell DJ, Kraus FT. Localized asymptomatic giant cell arteritis of the female genital tract. Int J Gynecol Pathol 1991;10:51-8.

8. Brack A, Martinez-Taboada V, Stanson A, Goronzy JJ, Weyand CM. Disease pattern in cranial and large-vessel giant cell arteritis. Arthritis Rheum 1999;42:311-17.

9. Schmidt WA. Imaging in vasculitis. Best Pract Res Clin Rheumatol 2013;27:107-18.

10. Weyand CM, Fulbright JW, Hunder GG, Evans JM, Goronzy JJ. Treatment of giant cell arteritis: interleukin-6 as a biologic marker of disease activity. Arthritis Rheum 2000;43:1041-8. 


\section{APPENDIX-SUPPLEMENTARY REFERENCES}

1. Doyle L, McWilliam L, Hasleton PS. Giant cell arteritis with pulmonary involvement. Br J Dis Chest 1988;82:88-92.

2. Kariv R, Sidi Y, Gur H. Systemic vasculitis presenting as a tumorlike lesion. Four case reports and an analysis of 79 reported cases. Medicine (Baltimore) 2000;79:349-59.

3. Ormsby AH, Haskell R. Giant cell arteritis of the uterus: case report and review. Pathology 1997;29:227-30.

4. Hernandez-Rodriguez J, Tan CD, Rodriguez ER, Hoffman GS. Gynecologic vasculitis: an analysis of 163 patients. Medicine (Baltimore) $2009 ; 88: 169-81$.

5. Bell DA, Mondschein M, Scully RE. Giant cell arteritis of the female genital tract. A report of three cases. Am J Surg Pathol 1986;10:696-701.

6. Buzzi A, Pezzica E, Crescini C, Sironi PL, Sonzogni A, Ziliani A. Giant-cell arteritis of the female genital tract. Minerva Ginecol 1993;45:425-8.

7. Gloor E, Schaller MD, Dubuis PY. Giant cell arteritis affecting the female genital tract. 2 case reports. J Gynecol Obstet Biol Reprod (Paris) 1982;11:785-8.

8. Hoen B, Baty V, Aymard B, Judlin P, Foliguet B, Canton P. Giant-cell arteritis of the female genital tract. J Intern Med 1994;236:345-7.

9. Lhote F, Mainguene C, Griselle-Wiseler V, Fior R, Feintuch MJ, Royer I, et al. Giant cell arteritis of the female genital tract with temporal arteritis. Ann Rheum Dis 1992;51:900-3.

10. Marrogi AJ, Gersell DJ, Kraus FT. Localized asymptomatic giant cell arteritis of the female genital tract. Int J Gynecol Pathol 1991;10:51-8.

11. Patel RK, Carrick K. Giant cell arteritis of the female genital tract: report of a case and review of the literature. South Med J 2005;98:469-71.

12. Petrides M, Robertson IG, Fox H. Giant cell arteritis of the female genital tract. Br J Obstet Gynaecol 1979;86:148-51.

13. Paccalin M, Le Moal G, Roblot P. Giant-cell arteritis of the female genital tract. Ann Intern Med 2001;134:626-7. 